\title{
NCAM-Associated Polysialic Acid on Ciliary Ganglion Neurons Is Regulated by Polysialyltransferase Levels and Interaction with Muscle
}

\author{
Juan L. Brusés, Shogo Oka, ${ }^{\mathrm{a}}$ and Urs Rutishauser \\ Departments of Genetics and Neurosciences, Case Western Reserve University, Cleveland, Ohio 44106
}

NCAM in its high polysialic acid (PSA) form is expressed on chick hindlimb motorneurons during their growth, and then decreases at about the time that synaptogenesis is completed. In order to characterize this regulation at the cell and molecular level, the present studies use the chick ciliary ganglion (CG) system, which constitutes a homogeneous and developmentally synchronized population of motoneurons that can be used for in vitro studies. Levels of PSA in the CG were evaluated both by SDS-PAGE immunoblot analysis of total NCAM and by pulse radiolabeling of newly synthesized NCAM. Up- and downregulation of PSA expression on newly synthesized NCAM in the CG was found to be closely correlated with in vivo innervation and synaptogenesis, respectively. Moreover, the downregulation observed at synaptogenesis was prevented by in vivo blockade of neuromuscular activity with $\alpha$-bungarotoxin. The developmental regulation of PSA expression was found to coincide precisely with an increase and decrease in levels of specific polysialyltransferase activity. By contrast, the expression of the VASE exon in NCAM, which in CNS is temporally correlated with PSA downregulation, was not expressed in the CG. Cocultures of CG neurons with myotubes were used to provide direct evidence that neuron-muscle interaction can cause a specific downregulation of both neuronal PSA and polysialyltransferase activity.

[Key words: NCAM, polysialic acid, ciliary ganglion, motoneurons, target dependent regulation, neuron-muscle interaction, polysialyltransferase, $\alpha$-bungarotoxin]

During development of the nervous system, axons follow precise trajectorics towards specific targets and innervate them in defined patterns. This process depends in part on the expression of specific surface molecules that mediate cell-cell interactions (for review, see Goodman and Shatz, 1993). For motoneurons in the chick embryo, changes in cell-cell interactions involving the neural cell adhesion molecule (NCAM) in its high polysialic acid (PSA) form, have been shown to play an important regu-

\footnotetext{
Received June 29, 1995; revised Aug. 23, 1995; accepted Aug. 24, 1995

We thank Dr. Lynn Landmesser for critique of the manuscript and Richard Nelson for assistance with the PCR screens. This work was supported in part by NIH Grants HD18369, EY06107, and NS19640.

Correspondence should be addressed to Urs Rutishauser, Department of Genetics, School of Medicine, Case Western Reserve University, 10900 Euclid Avenue, Cleveland, $\mathrm{OH} 44106-4955$.

"Present address: Department of Biological Chemistry, Faculty of Pharmaceutical Sciences, Kyoto University, Kyoto 606, Japan.

Copyright (C) 1995 Society for Neuroscience $0270-6474 / 95 / 158310-10 \$ 05.00 / 0$
}

latory role in both axon pathfinding and muscle innervation (see Rutishauser and Landmesser, 1991). PSA is expressed on motoneurons as their axons begin to grow, and its experimental removal at the time that axons are sorting out in the plexus region leads to guidance errors and inappropriate innervation of muscles (Tang et al., 1992, 1994). Moreover, PSA removal during the time the axons are growing in the muscles, increases axonal fasciculation and decreases axonal branching, which in turn decreases the number of neuromuscular junctions formed and impairs motoneuronal survival. After innervation of muscle is completed, PSA expression on the nerve is decreased (Landmesser et al., 1990; Tang and Landmesser, 1993).

PSA is an unusual NCAM-associated carbohydrate that can serve as a negative regulator of cell-cell interactions (see Troy, 1992; Rougon, 1993; Rutishauser, 1995). While the properties of PS $\Lambda$ that underlie this regulation have been described in some detail (Yang et al., 1992, 1994), little is known about the mechanisms by which the expression of PSA at the cell surface is regulated in the animal. PSA is synthesized on NCAM in the Golgi through the action of a recently described polysialytransferase (PST), after which the molecule is transported to the cell surface (Alcaraz and Goridis, 1991; Eckhardt et al., 1995; Nakayama et al., 1995). Its allachment to the fifth Iy domain of NCAM (Crossin et al., 1984) appears to involve specific recognition of NCAM polypeptide structures present in the adjacent Ig and fibronectin-like domains (Nelson et al., 1995). On this basis, a variety of possibilities for regulation can be considered: changes in the levels of PSA biosynthetic enzyme(s) (Eckhardt et al., 1995; Nakayama et al., 1995), alterations in the extracellular polypeptide structure of NCAM by alternative splicing (see Small et al., 1988; Walsh and Dickson, 1989), or modification of the cellular trafficking through the Golgi as obscrved with other sialoglycoproteins (Snider and Rogers, 1985).

The present study focuses on the cellular and molecular mechanisms by which the developmental regulation of PSA occurs in motoneurons. For this purpose the chick ciliary ganglion (CG) system has been chosen, as it contains only two motoneuronal populations with a similar timing of innervation of the internal eye muscles (Landmesser and Pilar, 1978). First, histological, biochemical, and pulse-label analyses of PSA expression in the CG were used to establish a correlation between neuronal PSA expression and the innervation of the target tissue. in vivo treatment with $\alpha$-bungarotoxin ( $\alpha$-BTX) was then utilised to demonstrate the role of neuromuscular activity on PSA expression in this system. The cellular mechanisms that could regulate PSA expression were addressed by studying the levels of a specific polysialyltransferase (PST) activity in the intact ganglion, and 
the expression of a variable alternative spliced exon (VASE). Finally, a cell culture system was used to investigate the importance of the interaction between CG neurons and muscle cells in the regulation of PSA and PST levels.

\section{Materials and Methods}

Immunohistochemistry. Chick CG were dissected from White Leghorn embryos of different ages, fixed in $4 \%$ paraformaldehyde for $30 \mathrm{~min}$ at room temperature, and placed in $30 \%$ sucrose overnight at $4^{\circ} \mathrm{C}$ for cryoprotection. The tissue was then embedded in OCT, frozen, and cryosectioned at $10 \mu \mathrm{m}$. NCAM distribution was visualized using a mouse monoclonal antibody (5E) that recognizes all chick NCAM isoforms (Watanabe et al., 1986), and polysialic acid was detected with the mouse IgM monoclonal antibody 5A5 (Acheson et al., 1991). Tissue sections were incubated with the primary antibody for $1-2 \mathrm{hr}$ at room temperature, then washed and stained with RITC-conjugated anti mouse IgG or FITC-conjugated anti-mouse IgM (Boehringer) for $1-2 \mathrm{hr}$. After rinsing, sections were mounted in glycerol diluted 1:1 with PBS $(137 \mathrm{~mm}$ $\mathrm{NaCl}, 2.6 \mathrm{~mm} \mathrm{KCl}, 10 \mathrm{~mm} \mathrm{Na} 2 \mathrm{HPO}_{4}, 1,7 \mathrm{~mm} \mathrm{KH} \mathrm{KH}_{2} \mathrm{PO}_{4}$ also conlaining $0.3 \mathrm{mg} / \mathrm{ml}$ phenylenediamine to prevent photobleaching. Pictures were taken with a Nikon Optiphot microscope with Kodak 125 Plus X-pan film.

Cell culture. CG were dissected from St 32-34 White Leghorn chick embryos (Hamburger and Hamilton, 1951) in cold oxygenated Tyrode's solution (134 mM NaCl, $3 \mathrm{~mm} \mathrm{KCl}, 20.5 \mathrm{~mm} \mathrm{NaHCO}, 3 \mathrm{~mm} \mathrm{CaCl}_{2}$, $1 \mathrm{mM} \mathrm{MgCl}_{2}$, and $12 \mathrm{mM}$ glucose, $\mathrm{pH}$ 7.2) and collected in $\mathrm{Ca}^{2+} \mathrm{Mg}^{2+}$ free Tyrode's. After $20 \mathrm{~min}$ trypsinization at $37^{\circ} \mathrm{C}(0.08 \%$ trypsin in $\mathrm{Ca}^{2+} \mathrm{Mg}^{2+}$ free Tyrode's) the ganglia were mechanically dissociated to a single cell suspension using a fire-polished Pasteur pipette in DMEM/ F12 (Dulbecco's modified Eagle's medium and Ham's F12 nutrient mix ture, $1: 1$; GIBCO) and supplemented with $0.1 \% \mathrm{BSA}$. To isolate the neurons from the non-neuronal cells present in the ganglion, the cell suspension was loaded on a discontinuous Percoll gradient $(30 / 60 \%$, $10: 1 \mathrm{ml}$ ) and centrifuged at $500 \times \mathrm{g}$ for $20 \mathrm{~min}$ at $4^{\circ} \mathrm{C}$ (Bruses and Pilar, 1995). The enriched neuronal fraction (approximate $90 \%$ neurons) located at the $30 \% / 60 \%$ Percoll interface was collected with a Pasteur pipette, washed with culture medium, counted in a hemocytometer, and plated in 24 well dishes precoated with poly-DL-ornithine $(0.2 \mathrm{mg} / \mathrm{ml})$ and laminin $\left(1 \mu \mathrm{g} / \mathrm{cm}^{2}\right)$, at a density of about 200,000 cells per well. DMEM/F12 supplemented with insulin $(5 \mu \mathrm{g} / \mathrm{ml})$, penicillin $(50,000$ U/liter) streptomycin $(50 \mathrm{mg} / \mathrm{liter})$, and $1.5 \% \mathrm{v} / \mathrm{v}$ (approximate $10 \mu \mathrm{g}$ of proteins/ml) soluble eye extract (CIPE) as trophic factor, was used as culture medium. This medium allows $100 \%$ survival of CG-derived neurons for at least a week.

Pectoral muscle from St 37 chick embryos was used as a source of myoblasts to generate a myotube culture. Briefly, pectoral muscle was dissected, cut into small pieces with surgical scissors, and mechanically dissociated with fire-polished Pasteur pipette. The cell suspension was briefly centrifuged to remove cell debris and undissociated tissue, and the cells counted in a hemocytometer and plated in 24 well dishes precoated with collagen (rat tail type 1 collagen, Collaborative Biomedical Products), at a density of 100,000 cells per well. The culture medium used was DMEM/F12 supplemented with $10 \%$ heat inactivated horse serum (HS) (GIBCO), 5\% chick embryo extract (CEE), and insulin $(5 \mu \mathrm{g} / \mathrm{ml})$. Two or $3 \mathrm{~d}$ after plating, the myoblasts had fused and formed long myotubes. At this time, the medium was replaced with DMEM/F12 supplemented with 5\% HS, 2\% CEE, insulin, and $1.5 \%$ CIPE, and CG neurons, prepared as described above, were plated on top of the myotubes. To obtain fibroblasts, the skin from St 37 chick embryo skulls was removed, trypsinized and dissociated by gentle trituration. Cclls were plated in 24 well dishes precoated with rat-tail collagen in the culture medium used for muscle. In about $3 \mathrm{~d}$ a monolayer of fibroblasts was obtained and used for coculture with neurons as above.

In ovo embryo drug treatment. White Leghorn chick embryos were raised in a force draft incubator at $37.5^{\circ} \mathrm{C}$. At St $25 / 26$ (Hamburger and Hamilton, 1951) a window $\left(1 \mathrm{~cm}^{2}\right)$ was opened on the shell and covered with a coverslip sealed with melted paraffin. $\alpha$-BTX (Sigma) (75 $\mu \mathrm{g}$ / $\mathrm{egg} / \mathrm{d})$ was injected onto the chorioallantoic membrane daily from St 26 to St 37 in $50 \mu 1$ sterile PBS.

Immunoblots and SDS-PAGE. Embryonic tissue was sonicated on ice in extraction buffer ( $25 \mathrm{~mm}$ HEPES, $1 \%$ Nonidet 40 (NP-40), $150 \mathrm{~mm}$ $\mathrm{NaCl}, 1 \mathrm{mM}$ PMSF, $1 \mathrm{~mm}$ EDTA, and $4.5 \mathrm{U} /$ liter aprotinin), incubated on ice for $30 \mathrm{~min}$, centrifuged at $15,000 \times g$ for $15 \mathrm{~min}$, and the protein concentration in the supcrnatant measured by the BCA method (Pierce). The supernatant was divided into two aliquots, with endoneuraminidase $\mathrm{N}$ (endo $\mathrm{N}$ ) being added to one of them, and both aliquots were incubated for 1 hr at $37^{\circ} \mathrm{C}$ to remove PSA (Hallemmeck et al., 1987). An equal volume of $2 \times$ sample buffer was added, the samples were heated at $65^{\circ} \mathrm{C}$ for $20 \mathrm{~min}$, and an equal amount of protein was loaded on each lane of a 6\% SDS-PAGE gel (Laemmli 1970) using a Bio-Rad minigel system. Gels were run at $180 \mathrm{mV}$ at $4^{\circ} \mathrm{C}$ for about $45 \mathrm{~min}$ and then proteins were electrotransferred to nitrocellulose filter paper. Filters were blocked for $60 \mathrm{~min}$ with phosphate buffer containing $50 \mathrm{gm} / \mathrm{liter}$ of nonfat dry milk and $20 \mu \mathrm{l} / \mathrm{liter}$ antifoam A (Sigma), and then incubated with a rabbit polyclonal IgG anti-chick NCAM antibody (RO32) overnight at $4^{\circ} \mathrm{C}$. After rinsing the blots with PBS, they were incubated with HRP-conjugated anti-rabbit IgG, and finally developed using the ECL system (Amersham). Appropriate exposures were obtained using Hyperfilm film (Amersham).

Pulse labeling and immunoprecipitation. Intact CG were dissected and collected in DMEM-HEPES culture medium without methionine and incubated for $30 \mathrm{~min}$ at $37^{\circ} \mathrm{C}$. The medium was then replaced with the same medium containing $300 \mu \mathrm{Ci} / \mathrm{ml}$ of $\mathrm{L}^{-35} \mathrm{~S}$-methionine (Amersham, specific activity $1000 \mathrm{Ci} / \mathrm{mmol}$ ) and incubated at $37^{\circ} \mathrm{C}$ for the pulse time specified, followed by a wash with ice-cold culture medium containing $3 \mathrm{~mm}$ nonradioactive methionine, and a chase in the same medium at $37^{\circ} \mathrm{C}$. After the chase, the tissue was homogenized by sonication in extraction buffer, centrifuged at $100,000 \times g$ for $30 \mathrm{~min}$, and the supcrnatant adsorbed overnight at $4^{\circ} \mathrm{C}$ with monoclonal 5E-conjugated Sepharose beads (CNBr-activated, Pharmacia). The immunobeads were then washed three times with washing buffer $(50 \mathrm{~mm}$ Tris- $\mathrm{HCl} \mathrm{pH}$ $8.0,0.5 \mathrm{M} \mathrm{NaCl}, 1 \% \mathrm{NP}-40,1 \mathrm{~mm}$ EDTA) and three times with a second washing buffer $(50 \mathrm{~mm}$ Tris- $\mathrm{HCl} \mathrm{pH} 8.0,150 \mathrm{~mm} \mathrm{NaCl}, 0.5 \% \mathrm{NP}-40$, $0.1 \%$ SDS) (Schneider et al., 1982). The beads were resuspended in extraction buffer, and the sample split in two parts, one of them being treated with endo $\mathrm{N}$ for $1 \mathrm{hr}$ at $37^{\circ} \mathrm{C}$. Samples were then run on SDSPAGE as described for immunoblots, the gel fixed for $30 \mathrm{~min}$ in propanol:water:acetic acid (25:65:10) and dried. Direct autoradiograms were obtained using Kodak Biomax film. Occasionally, fluorograms were performed by incubating the gel for $30 \mathrm{~min}$ in $\Lambda$ mplify ( $\Lambda$ mersham) before drying and fluorographs obtained by suitable exposure of preflashed Hyperfilm-MP (Amersham). A similar procedure was used to pulse label cultured tissue. After the radioactive medium was washed out, cells were removed by adding PBS containing 5 mM EDTA and transferred to a $1.5 \mathrm{ml}$ tube prior to sonication in extraction buffer.

VASE detection by RT-PCR. Approximately 50 chick CGs from $\mathrm{St}$ 33,37 , and 40 chick embryos were harvested and total RNA was isolated using the Ultraspec RNA isolation system (Biotex). Total RNA from St 41 chick brain was used as positive control for the presence of VASE. Total RNA was reverse transcribed with random hexamers and PCR was performed with a GeneAmp RNA PCR kit (Perkin Elmer Cetus) using for amplification two primers (100 pmol each) targeted to the translated region of the fourth Ig domain of chick NCAM and flanking the region where VASE is inserted: 5'-AAACCCAAAATCACATATGTG-3' (1162-1182) and 5'-TGGGAGCATACTGCAC-3' (14471462). The predicted PCR products were 320 bp for the NCAM mRNA lacking the VASE insertion, and 350 bp for NCAM mRNA with VASE. After 35 cycles $\left(30 \mathrm{sec}, 94^{\circ} \mathrm{C}, 1 \mathrm{~min} 55^{\circ} \mathrm{C}\right.$, and $1 \mathrm{~min} 72^{\circ} \mathrm{C}$ ), PCR products were separated by $2 \%$ agarose gel electrophoresis, stained with ethidium bromide, visualized under UV light, and recorded by Polaroid photography.

Polysialyltransferase assay. CG were homogenized in $0.37 \mathrm{M} \mathrm{su-}$ crose, $10 \mathrm{~mm}$ MES pH 6.0, $1 \mathrm{~mm}$ EDTA, $1 \mathrm{mM}$ PMSF, and $4.6 \mathrm{U} /$ liter aprotinin. After being centrifuged at $10,000 \times g$ for $10 \mathrm{~min}$, the pellet was sonicated in extraction buffer ( $1 \%$ NP-40, 10 mM MES pH 6.0, 1 mM EDTA, $1 \mathrm{~mm}$ PMSF, and $4.6 \mathrm{U} /$ liter aprotinin), and glycerol was added to a final concentration of $30 \%$. The reaction solution contained the following components in a total vol of $50 \mu \mathrm{l}: 20 \mu \mathrm{l}$ of the CG extract, $10 \mu \mathrm{g}$ of purified El 4 chick brain NCAM, $10 \mu \mathrm{M}$ CMP- ${ }^{14} \mathrm{C}-\mathrm{N}-$ acetylneuraminic acid $(286 \mathrm{mCi} / \mathrm{mmol}$; Amersham), $100 \mathrm{mM}$ MES buffer, pH 6.0, $20 \mathrm{mM} \mathrm{MnCl}$, and $2.5 \mathrm{mM}$ ATP. After incubation for $3 \mathrm{hr}$ at $37^{\circ} \mathrm{C}$, the reaction was terminated by addition of EDTA at a final concentration of $50 \mathrm{~mm}$. To determine if the incorporation of ${ }^{14} \mathrm{C}-\mathrm{N}$ acetylneuraminic acid into NCAM was in the form of an $\alpha 2,8$-linked polysialic acid chain, the sample was divided in two aliquots and one of them treated with endo $N$, which specifically degrades $\alpha-2,8$-linked polysialic acid, for $1 \mathrm{hr}$ at $37^{\circ} \mathrm{C}$. The samples were then spotted onto $2.5 \mathrm{~cm}$ Whatmann DE81 paper disks, rinsed three times in $20 \mathrm{mM}$ MES 

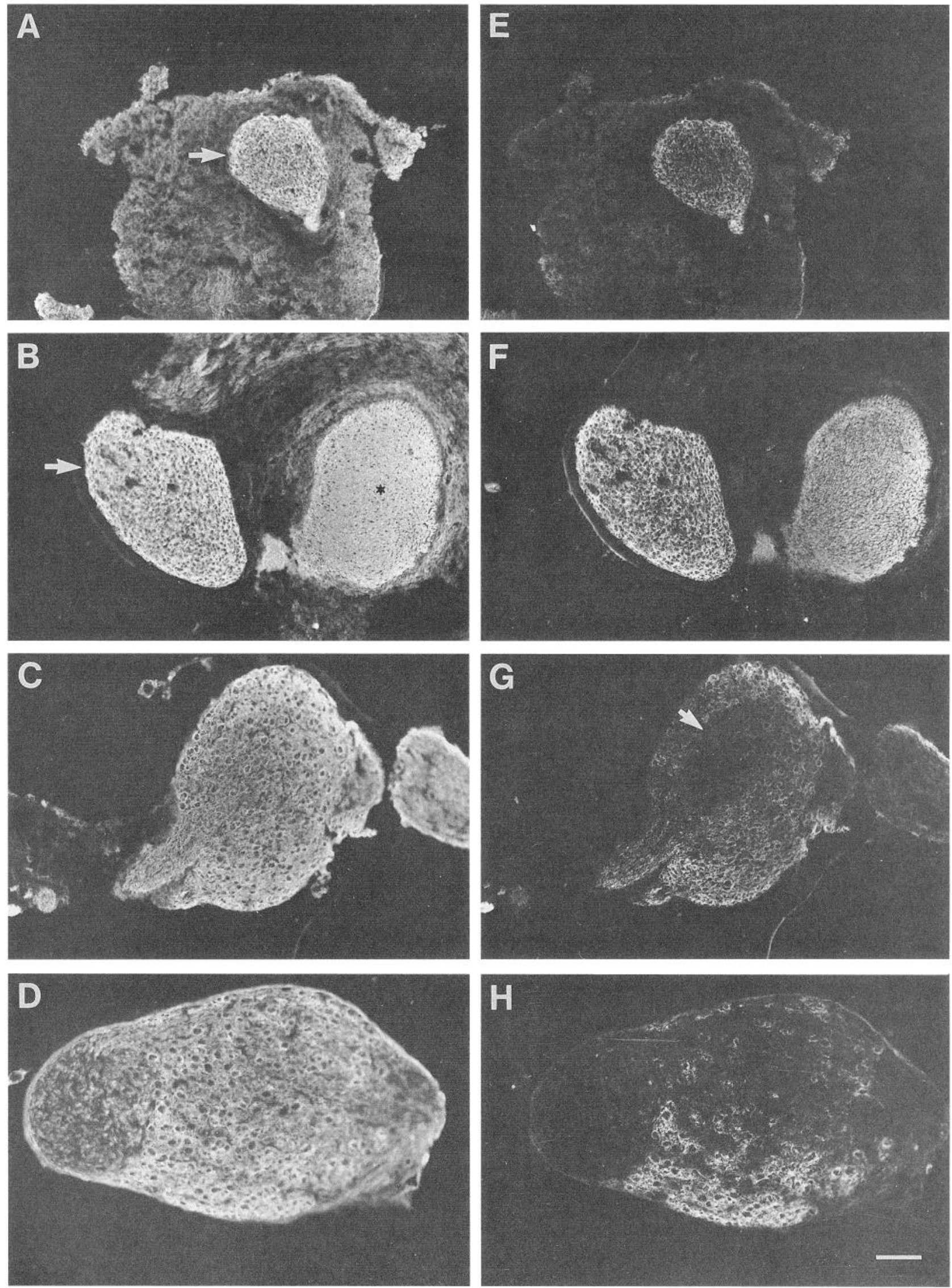

Figure 1. Developmental regulation of NCAM and PSA expression in the CG. Frozen sections of CG from various embryonic stages were double stained for NCAM $(A-D)$ and PSA $(E-H)$. At St 27, when neuronal processes are growing as a bundle towards the muscle target, NCAM was 
buffer, pH $6.0,250 \mathrm{~mm} \mathrm{NaCl}$, once with $95 \%$ ethanol, air-dried, and the radioactivity in the discs was measured in a Beckman scintillation counter. The difference in the amount of counts between control samples and endo $\mathrm{N}$ treated samples was taken as a measure of the amount of sialic acid that had been enzymatically incorporated into $\alpha 2,8$-linked polysialic acid chains. Specific activity at each stage analyzed was calculated with respect to either total protein as determined by the $\mathrm{BCA}$ assay (Pierce) or total NCAM as assessed from densitometric scans of the SDS-PAGE immunoblots described above.

\section{Results}

Developmental regulation of NCAM and PSA expression in the $C G$

To identify the temporal pattern of expression of NCAM and PSA during embryonic development of the chick CG, frozen sections from St 27, 32, 37, and 42 were double-stained with monoclonal antibody $5 \mathrm{E}$, which recognizes all isoforms of chick NCAM (Watanabe et al., 1986), and monoclonal antibody 5A5, which specifically detects PSA (Acheson et al., 1991). At early stages of development (St 27), shortly after the CG has been formed and its neuronal processes are reaching their target tissues (Landmesser and Pilar, 1978), NCAM was found to be homogeneously expressed on the neuronal bodies of the ganglion, but there was little expression of PSA (Fig. 1A,E). By St $32 / 33$, when the axons are growing in the internal muscles of the eye and start to branch (Meriney and Pilar, 1987), the expression of PSA increased in the cell bodies of the ciliary and choroid population (Fig. $1 F$ ). The period of synapse formation of the CG neurons on eye muscles starts at St 35/36 and ends by St 40 . During this period, when neurons compete for their target and half of the neurons in each population die, a decrease in the expression of PSA was detected in both neuronal populations, but mainly with cells identified as ciliary neurons by their position in the ganglion (Pilar et al., 1980) (Fig. 1G,H). In general, changes in NCAM expression from St 27 to 42 were less apparent, although a smaller decrease in NCAM staining appeared to accompany the large decrease in PSA at St 37 (Fig. $1 G)$.

Biochemical characterization of NCAM isoforms at different developmental stages was carried out by SDS-PAGE immunoblot analysis using a polyclonal antibody that recognizes all isoforms of chicken NCAM. To determine whether or not the NCAM was polysialylated, a sample was treated with endo $\mathrm{N}$ prior to electrophoresis and the disappearance of polydisperse material with a low mobility (above $200 \mathrm{kDa}$ ), together with the appearance or intensification of distinct polypcptide bands was taken as an indication of the presence of PSA. At St 26, the 140 and $180 \mathrm{kDa}$ polypeptide isoforms (NCAM-140 and NCAM180 ) were detected and both were polysialylated (Fig. $2 A$, lanes 1 and 2). A similar pattern was found at St 33, but with a higher degree of polysialylation as indicated by the lower average mobility of the material prior to endo $\mathrm{N}$ treatment. At St 37 there was a detectable decrease in PSA as indicated by a lighter staining of the polydisperse region, particularly at low mobilities, and the presence of a $140 \mathrm{kDa}$ band prior to endo $\mathrm{N}$ treatment (Fig. $2 A$, lanes 5 and 6 ). By the time synaptogenesis and the natural cell death period have ended ( $\mathrm{St} \mathrm{42),} \mathrm{the} \mathrm{total} \mathrm{amount} \mathrm{of} \mathrm{PSA}$ detected in the immunoblot was lower than at all previous stages. This decrease was substantially due to nonpolysialylation of a large portion of the NCAM-140, and a lower level of polysialylation of NCAM-180. Thus, the amount of PSA revealed by SDS-PAGE immunoblots corresponded with the up- and downregulation of PSA immunostaining in the CG during development. Some changes in NCAM polypeptide isoforms could also be detected, namely fluctuations in the relative amounts of NCAM-140 and NCAM-180, and the appearance of a nonpolysialylated $120 \mathrm{kDa}$ isoform (NCAM-120) at St 42 (Fig. $2 A$, lanes 7 and 8 ).

These findings were confirmed qunatitatively by densitometric scanning of the immunoblots. The material running above 250 $\mathrm{kDa}$, which corresponds to the most highly polysialylated NCAM, was determined relative to the total amount of NCAM (sum of the 180 and $140 \mathrm{kDa}$ polypeptides after treatment with endo N). At St 26, 24\% of the NCAM was in this highly polysialylated fraction, and by $\mathrm{St} 33$, this value increased to $40 \%$. Thereafter, there was a decrease to $31 \%$ at St 37 and $25 \%$ at St 42.

To determine more precisely the time of downregulation of NCAM polysialylation, an analysis of newly synthesized NCAM was performed by pulse-labeling intact $\mathrm{CG}$ with ${ }^{35} \mathrm{~S}$-methionine. The pattern of synthesis at St 26 (Fig. 2B, lanes 1 and 2) was similar to that detected by immunoblot analysis (the same lanes in Fig. 2A). That is, the NCAM-180 and NCAM-140 isoforms were both synthesized and polysialylated. At St 33, the same relationship between synthesis and the immunoblots was observed (lanes 3 and 4 in Fig. $2 A, B$ ), except that the average mobility of the polysialylated material was lower, suggesting the presence of longer polysilaic acid chains. However, at St 37 the polysialylation of newly synthesized NCAM was even more dramatically reduced (Fig. 2B, lanes 5 and 6), and at St 42 NCAM180 was still being synthesized but was no longer being polysialylated (Fig. 2B, lanes 7 and 8 ). To rule out the possibility that at St 40 NCAM polysialylation had occurred at a slower rate, intact $C G$ were pulse-labeled and chased for up to $6 \mathrm{hr}$; under these conditions, polysialylation of NCAM-180 was still not observed (data not shown).

\section{The mechanism of regulation of NCAM polysialylation in the $C G$}

The regulation of the polysialylation of NCAM could take place at many steps during the synthesis and processing of the molecule. Two major steps in this process have been correlated with PSA regulation in other systems: the alternative splicing of NCAM mRNA to insert the VASE exon between exons 7 and 8 in the fourth Ig domain (Small and Akeson, 1990), and the level of polysialyltransferase activity in the Golgi (McCoy et al., 1985; Alcaraz and Goridis, 1991). VASE is proposed to be a negative regulator in that it is absent at early stages of development in chick brain but it is detected at later stages when the expression of PSA decreases (Oka et al., 1995).

\section{$\leftarrow$}

present in the CG (arrow in A) but relatively little PSA was detected $(E)$. By St 32 , the axons are spreading into the muscle prior to synapses formation and PSA expression $(F)$ on the neuronal body was highly increased while NCAM levels in the CG remained constant (arrow in $B$; the asterisk indicates the optic nerve). At St 37, when CG neurons are competing among each other for the target tissue and many have already made synapses, the expression of PSA $(G)$ was significantly reduced mainly in the ciliary population $(G$, arrow) while NCAM expression was only slightly reduced $(C)$. By St 42 the natural cell death period has ended and the remaining neurons have functional neuromuscular junctions. At this time the level of PSA $(H)$ has returned to nearly undetectable levels while again the NCAM $(D)$ expression remained constant. Scale bar, $100 \mu m$. 
Figure 2. Biochemical characterization of NCAM and PSA expression in CG. A, SDS-PAGE immunoblot stained with an anti-chick NCAM antibody that recognizes all NCAM isoforms. Lane labels: $(+)$ and $(-)$ indicate endo $\mathrm{N}$-treated and untreated samples respectively; lanes 1 and 2, St 26; lanes 3 and 4 , St $32 / 33$; lanes 5 and 6 , St 37 ; and lanes 7 and 8 . St 42 . Note that the amount of PSA is the highest at St 33 and declines gradually thereafter. $B, \mathrm{Im}$ munoaffinity isolated NCAM from intact CG pulse-labeled with ${ }^{35} \mathrm{~S}$-methionine. At St 26 (lanes 1 and 2; 1 hr pulse) and St 33 (lanes 3 and 4; 1 hr pulse) the newly synthesized NCAM is fully polysialylated. By St 37 (lane 5 and 6;2 hr pulse), the level of polysialylation has decreased and by St 42 (lanes 7 and 8 ; $2 \mathrm{hr}$ pulse) no NCAM polysialylation is detected. In order to compensate for the natural loss of cells during development, the number of ganglia used at each stage were 16 at St 26, 15 at St 33, and 25 at St 37 and St 40.
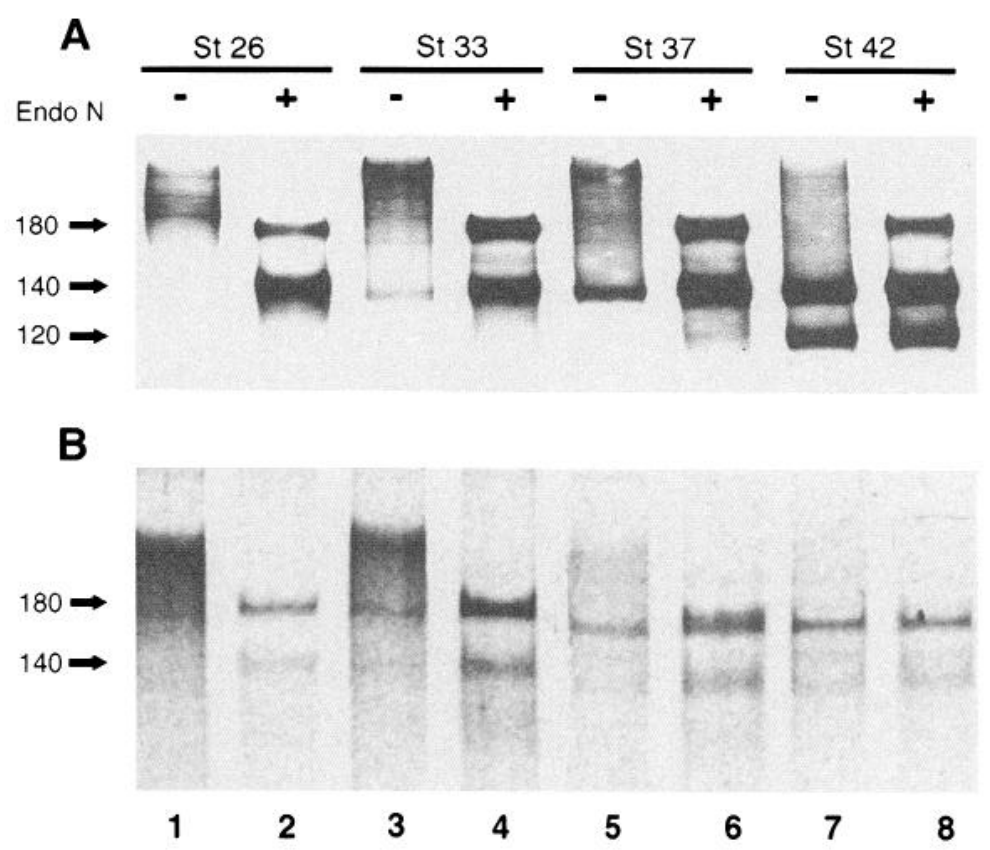

In the present studies, the presence of VASE exon on NCAM RNA in CG neurons was tested at St 33, 37, and 41 by the RTPCR method using two primers flanking the region where VASE is inserted. Thus, if NCAM mRNA contains the VASE exon, its PCR products should be $30 \mathrm{bp}$ larger ( $350 \mathrm{bp}$ ) than the PCR product of NCAM mRNA without VASE (320 bp). Although PSA synthesis changed markedly over the three stages studied, only the 320 bp could be detected (Fig. 3, lanes 1-3). Chick brain RNA from a St 41 embryo was used as a positive control for the detection of VASE, and two bands of the predicted size for NCAM with and without VASE were detected (Fig. 3, lane 4). These results suggest that the VASE exon does not play a major role in the developmental downregulation of PSA expression by CG motorneurons.

To study quantitatively the polysialyltransferase (PST) activity in CG neurons, an assay (modified from McCoy et al., 1985) was developed that measures the incorporation of radioactive $\mathrm{N}$-acetylneuraminic acid into $\alpha$-2,8-linked PSA chains on purified exogenous NCAM. Pools of CG from stages 26-27, 33-34, $36-38$, and 40 were homogenized, extracted with detergent, and the enzymatic activity measured. The specific activity at each stage was determined with respect to either total protein or the relative amount of NCAM expressed. As shown in Figure 4, the level of PST specific activity present in CG increased from St 26-27 to St 33-34. Between St 33-34 and St 36-38 the level of PST activity decreased, and by the end of the embryonic development (St 40) little activity could be detected in the ganglion. Thus the timing of the observed increase and decrease in activity mirrored the developmental up- and downregulation of PSA observed in the immunohistology, immunoblot and pulse label experiments.

\section{Effect of neuromuscular activity blockade on PSA expression}

Previously, it was found that activity blockade with curare increases the expression of PSA on intramuscular nerve branches and sciatic nerve at the time spinal cord motoneurons are innervating the chick hind limb (Landmesser et al., 1990). To study the possible role of neuromuscular activity on the regulation of PSA synthesis, chick embryos were treated daily from St 26 to 37 with $75 \mu \mathrm{g}$ of $\alpha$-BTX. This treatment has been shown to be effective in rescuing both ciliary and choroid neuronal populations in the CG during the cell death period (Meriney et al., 1987). At the time the natural PSA down-regulation is observed (St 37), the ganglia were harvested and PSA synthesis on newly synthesized NCAM was measured by pulselabeling with ${ }^{35} \mathrm{~S}$-methionine followed by immunoaffinity
Figure 3. VASE expression in CG neurons. Total RNA was isolated from St 33, 37, and 40-41 CG, and amplified by RT-PCR with primers flanking the VASE region. PCR products were separated by agarose gels and stained with ethidium bromide. Lane 1, 100 bp DNA standard; lane 2, St 33 CG; lane 3, St 37 CG; lane 4, St 40-41 CG; and lane 5 , St 41 chick brain. In chick brain two bands are detected, one at $320 \mathrm{bp}$ that corresponds to the NCAM RNA without the VASE exon and another at 350 that represents the VASE insertion. By contrast, the $350 \mathrm{bp}$ VASE-positive band was not detected in CG at the three stages tested.

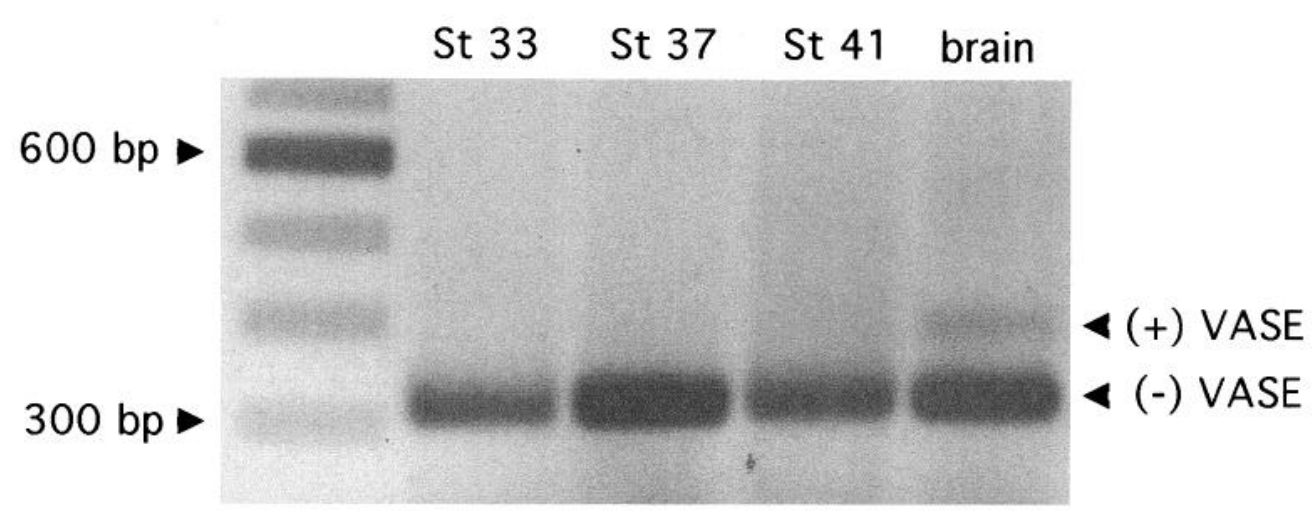




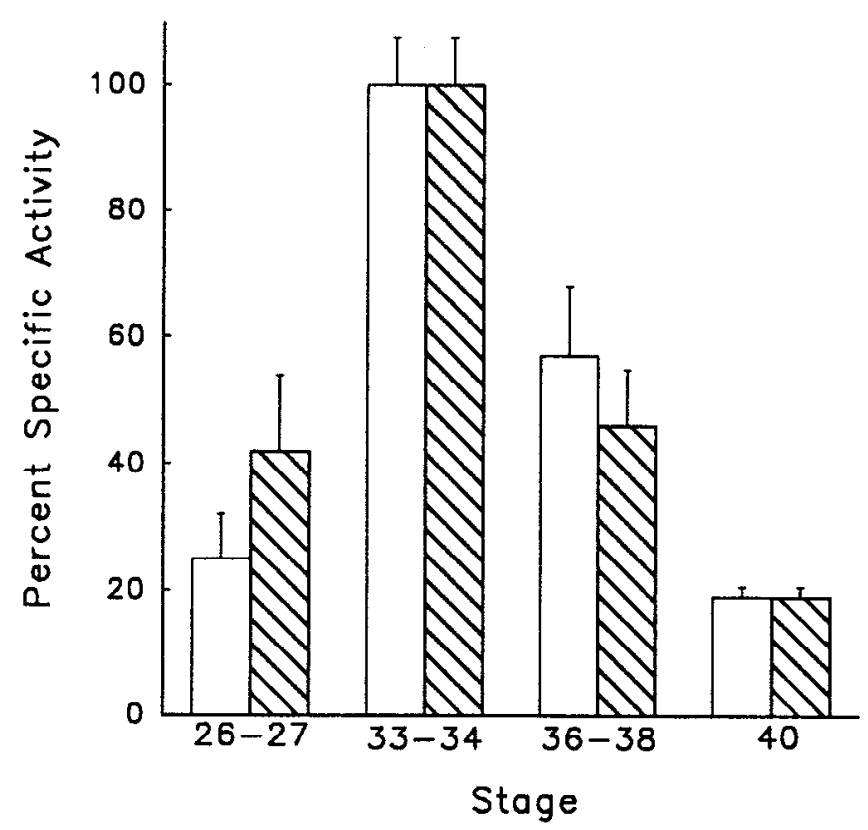

Figure 4. Developmental changes in CG polysialyltransferase activity. Approximately $50 \mathrm{CG}$ were collected from the indicated stages and the enzyme activity extracted from a membrane fraction. Enzymatic assays were carried out as described in Materials and Methods. Data $( \pm \mathrm{SE}$ from three independent experiments performed in duplicate) are presented as the percent of maximal specific activity $(32 \mathrm{pmol} / \mathrm{mg}$ total protein/hr at St 33-34) relative to total protein (open bars) or total NCAM (hatched bars).

isolation of NCAM, SDS-PAGE, and autoradiography. The relative amounts of NCAM isoforms and their degree of polysialylation was evaluated by densitomctric scanning of the autoradiogram (Fig. 5). Figure $5 A$ shows a densitometric scans of $\mathrm{St}$ $33 \mathrm{CG}$, before synaptic activity can be detected (Landmesser and Pilar, 1974; Meriney and Pilar, 1987). The arrow and arrowhead indicate polysialylated NCAM and the NCAM-180 isoform, respectively; note that most of the NCAM is polysialylated. In contrast, by ST 37 when neuromuscular junctions are active, a large decrease in PSA was observed and a corresponding increase in the nonpolysialylated NCAM-180 was detected (Fig. 5B). However, if the neuromuscular activity was chronically blocked by $\alpha$-BTX, the reduction in NCAM polysialylation which normally occurs by ST 37 was largelly prevented (Fig. $5 C$, arrow). When PSA was removed from these samples by endo $\mathrm{N}$ treatment prior to electrophoresis, the relative amounts of the NCAM-180 and NCAM-140 isoforms were not affected by $\alpha$-BTX treatment (data not shown). By contrast, the degree of NCAM polysialylation was $34 \%$ higher in the $\alpha$-BTX treated embryos as compared to untreated controls.

\section{Kinetics of NCAM polysialylation and NCAM turnover in cultured $C G$ neurons}

To investigate the role of cell-cell interactions in regulation of PSA on CG motorneurons, studies were carried out with culturcd cells. Figure $6 A$ shows a 1 d old culture of St $33 \mathrm{CG}$ neurons grown on laminin and immunostained with an anti-PSA antibody; Figure $6 B$ shows the same neurons cocultured with myotubes. Neurons are indicated by arrows and myotubes by arrowheads. First, in order to obtain a more accurate assessment of PSA synthesis in the culture system, pulse-chase experiments were conducted to determine the kinetics of NCAM polysialy-
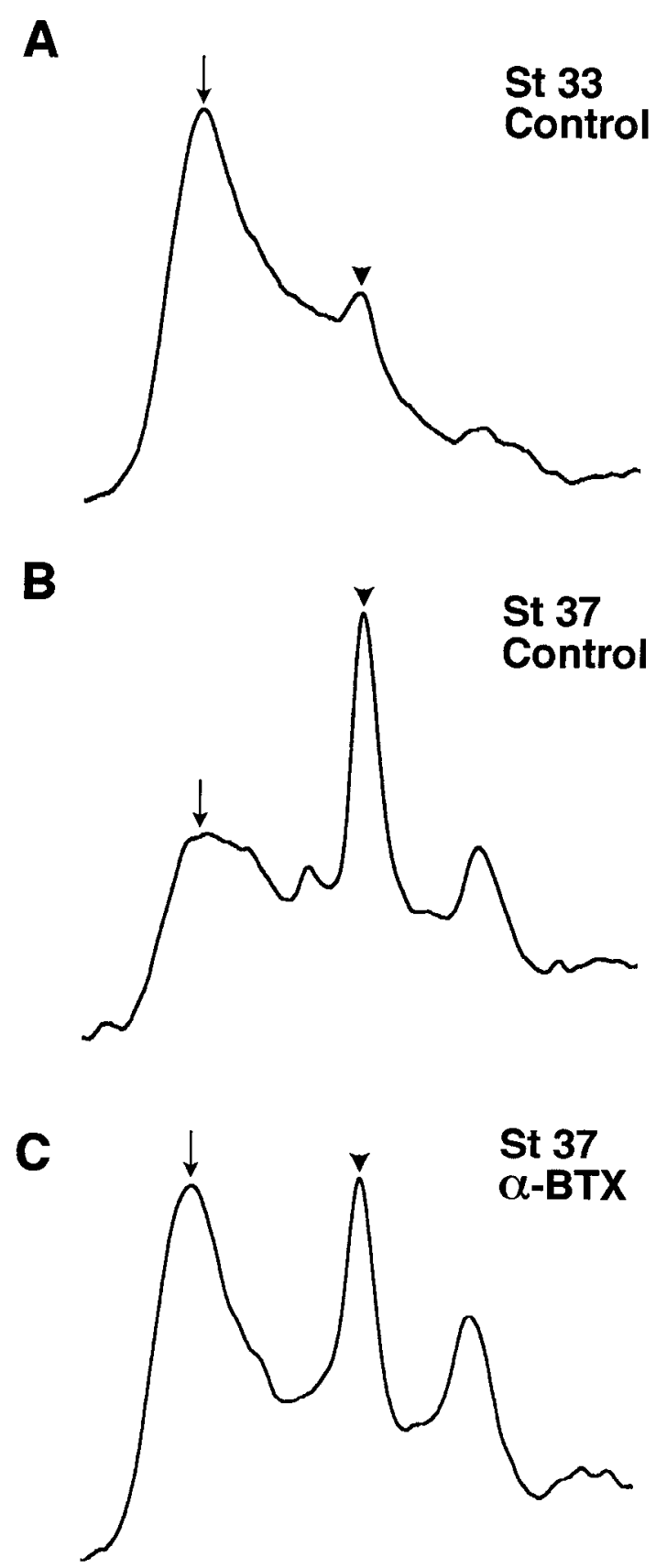

Figure 5. In vivo effect of chronic neuromuscular activity blockade on NCAM polysialylation in the CG. Densitometric scans of pulse-labeled, immunoprecipitated NCAM after SDS-PAGE $(A)$ at St 33, $(B)$ at St 37, and $(C)$ at St 37 treated with $\alpha$-BTX from St 26-37. Note that the normal developmental reduction in NCAM-PSA (arrows in $A$ and $B$ ) is largely prevented by $\alpha$-BTX treatment (arrow in $C$ ). The arrowheads indicate unsialylated NCAM-180, which increases as PSA-NCAM decreases.

lation and turnover in CG neurons in culture. In these studies the shift in the electrophoretic pattern of NCAM, from a sharp band at $180 \mathrm{kDa}$ to a smear above $200 \mathrm{kDa}$, was taken as evidence for the presence of PSA chains on NCAM. CG neurons were cultured for $1 \mathrm{~d}$ prior to a pulse with ${ }^{35} \mathrm{~S}$-methionine for $30 \mathrm{~min}$ and a chase for the indicated time (Fig. 7A). At the end of the pulse, a clear $180 \mathrm{kDa}$ band was detected which remained constant in intensity over the next half hour. A shift in the migration pattern of NCAM 180 was detected at the $1.5 \mathrm{hr}$ time- 

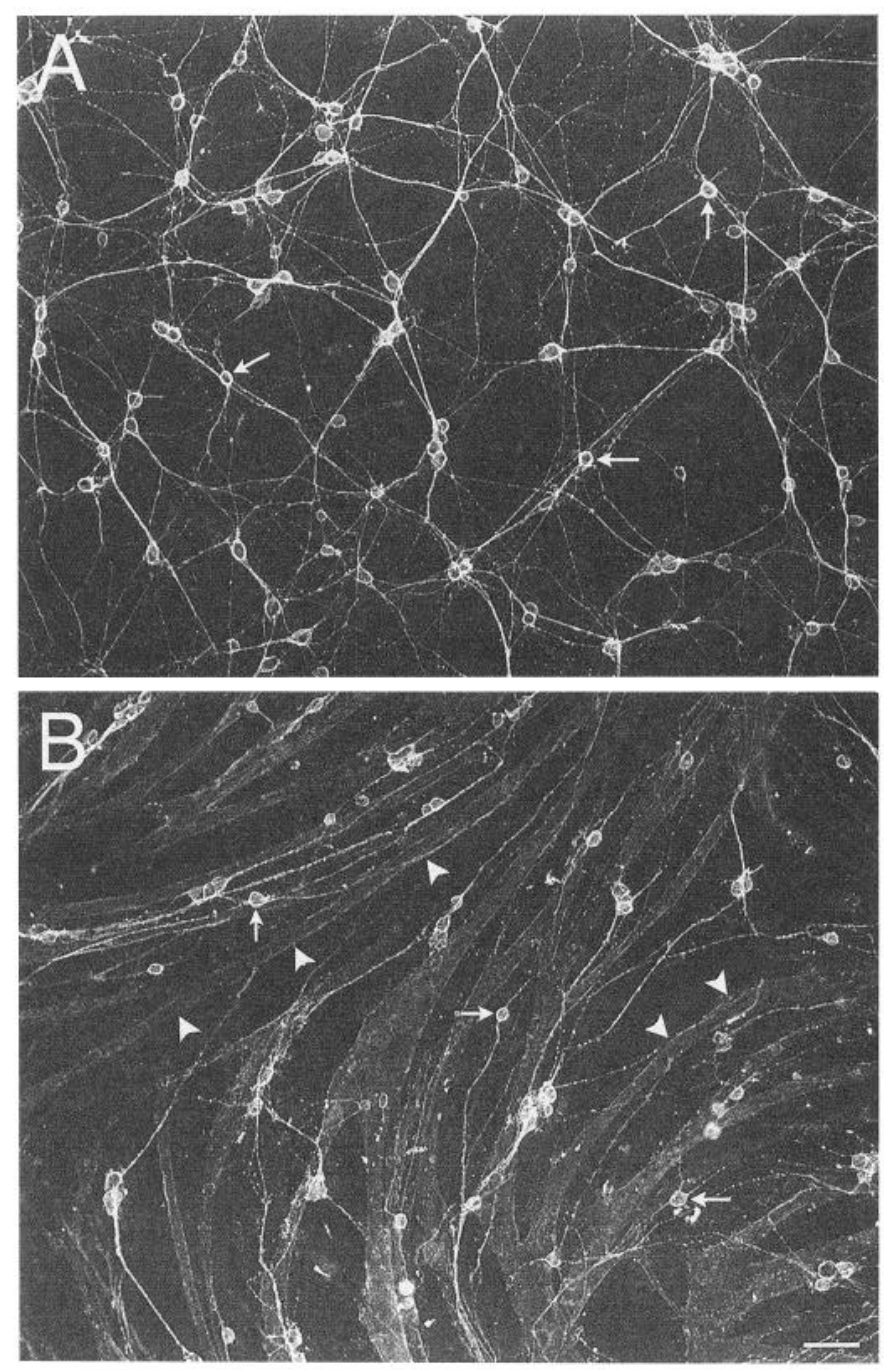

Figure 6. Cultures of St 33 CG neurons on laminin $(A)$ and with muscle myotubes $(B)$, visualized $1 \mathrm{~d}$ after plating by fluorescence microscopy after staining for PSA. Note that in both cultures the neurons (arrows) send out long processes. In the presence of the myotubes (arrowheads), these processes tend to course along the muscle cell surfaces. Scale bar, $50 \mu \mathrm{m}$.

point, indicating that between $0.5 \mathrm{hr}$ and $1.5 \mathrm{hr}$ the labeled NCAM had became polysialylated. The synthesis appeared to occur in a single step in that no intermediate bands were detected. A rapid rate of synthesis of PSA is consistent with the kinetics observed in AtT-20 cells (Alcaraz and Goridis, 1991), where newly synthesized NCAM with PSA occurs after only about $10 \mathrm{~min}$.

The kinetics of NCAM polysialylation in intact St 33 ganglia was similar to that observed with cultured CG neurons. However complete polysialylation of NCAM in intact ganglia was observed already at $30 \mathrm{~min}$, suggesting that in vivo synthesis of PSA may be faster than in vitro (data not shown). After this initial synthesis, PSA chains on NCAM did not appear to be altered further, in that the electrophoretic pattern remained unchanged up to $8 \mathrm{hr}$ (Fig. 7A).

To define the half-life of NCAM in cultured neurons, St 33 $\mathrm{CG}$ neurons were cultured for $1 \mathrm{~d}$, pulsed with ${ }^{35} \mathrm{~S}$-methionine for $2 \mathrm{hr}$, and then chased for 24 or $48 \mathrm{hr}$. The immunoprecipitated NCAM was treated with endo $\mathrm{N}$ to remove PSA and sep-
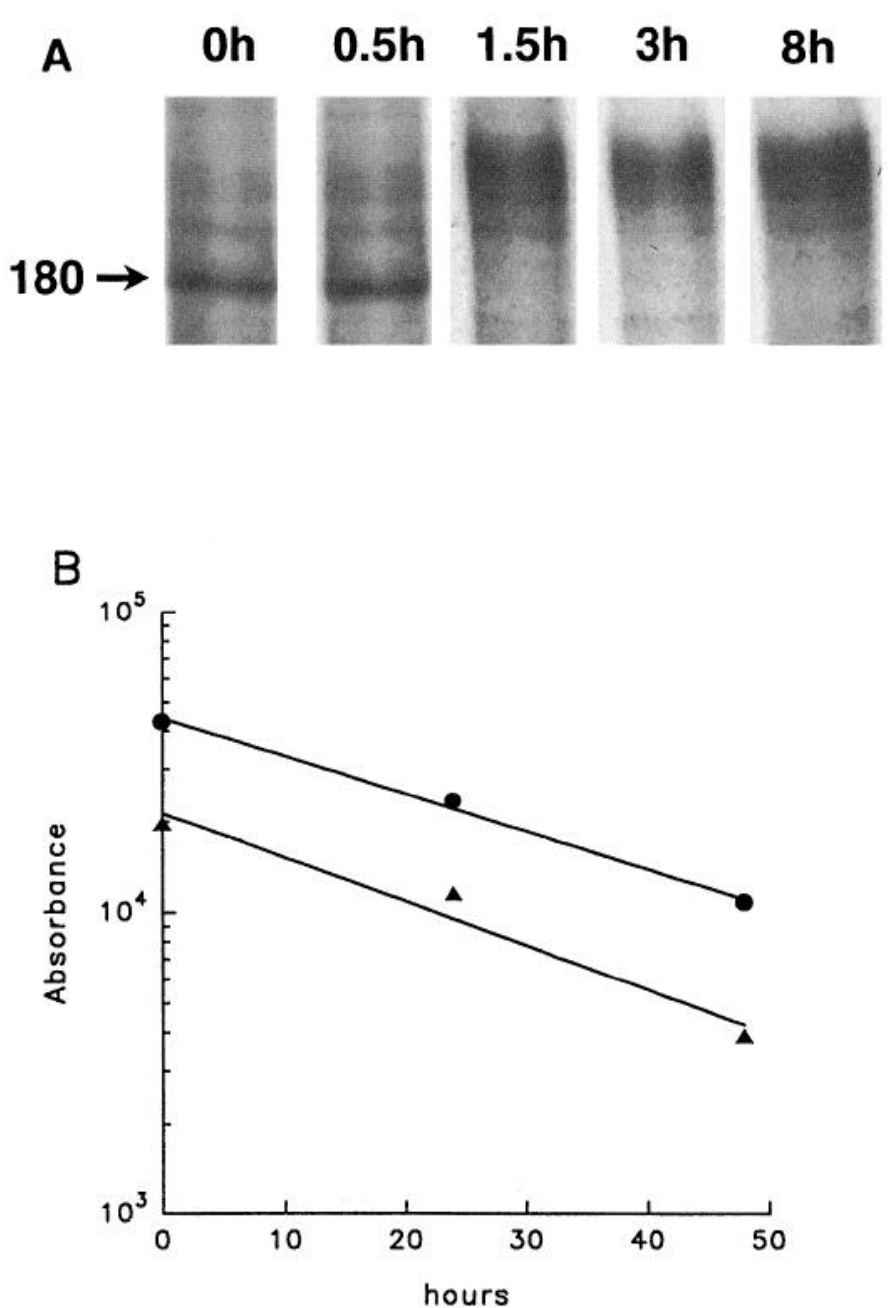

Figure 7. Kinetics of NCAM polysialylation and turnover in CG neurons. One day old cultures of St $33 \mathrm{CG}$ neurons were pulse labeled with ${ }^{35} \mathrm{~S}$-methionine for $30 \mathrm{~min}$ and chased for the indicated times. The immunoaffinity isolated NCAM extracted from these cells was detected by autoradiography after SDS-PAGE, and the relative absorbance of each band on the autoradiogram was measured to quantify the amount of NCAM present. $A$, Thirty minutes after the end of the pulse NCAM 180 was still not polysialylated, but after a $1.5 \mathrm{hr}$ chase polysialylation was complete. $B$, Equivalent cultures labeled with ${ }^{35} \mathrm{~S}$-methionine for 2 $\mathrm{hr}$, chased for 0,24 , and $48 \mathrm{hr}$, and the extracted samples treated with endo $\mathrm{N}$ prior to immunoaffinity isolation and SDS-PAGE. From these semilog plots the estimated half-life for NCAM-180 (circles) and NCAM-140 (triangles) are 25 and $23.5 \mathrm{hr}$, respectively.

arated by SDS-PAGE. A semilog plot of the relative amounts of NCAM-180 and NCAM-140 isoforms is shown in Figure $7 B$. The half-lives estimated from these data were 25 and $23.5 \mathrm{hr}$ for NCAM-180 and NCAM-140, respectively (Fig. 7B).

\section{Muscle cells specifically downregulate both NCAM} polysialylation and PST activity in cultured CG neurons

The above in vivo results indicate that by the time CG neurons are innervating their target, the expression of PSA by these cells is downregulated. To determine whether the downregulation of PSA was caused by direct interaction of the neurons with muscle, in vitro experiments were performed in which St $33 \mathrm{CG}$ neurons were cultured either alone or with cultured myotubes derived from St 37 pectoral muscle. CG neurons cocultured with myotubes are known to differentiate and make functional neu- 

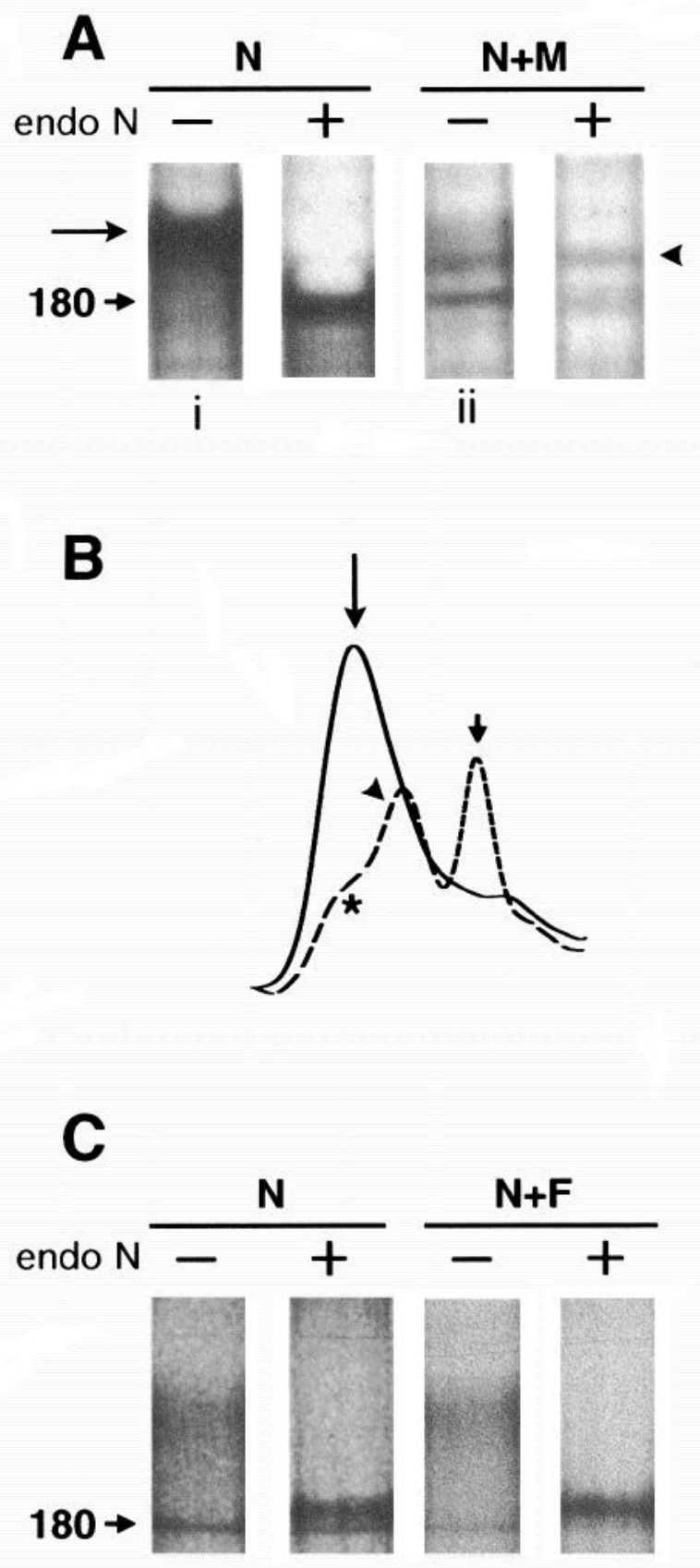

Figure 8. Effect of muscle cells on neuronal NCAM polysialylation in cultures. CG neurons were cultured either alone or with myotubes for $3 \mathrm{~d}$. Cultures were then pulse-labeled with ${ }^{35} \mathrm{~S}$-methionine, the NCAM extracted and immunoprecipitated, and endo N-treated (+) or untreated $(-)$ samples run on SDS-PAGE followed by autoradiography. $A$, Cultures containing CG neurons alone $(N)$, or neurons and myotubes $(N+M)$. Neurons cultured alone synthesized NCAM-180 that is heavily sialylated; however, the presence of muscle $(N+M)$ dramatically reduced polysialylation of NCAM-180 so that the NCAM-180 band is observed in the endo N-untreated sample. The band above $200 \mathrm{kDa}$ observed in the cocultures represents an unidentified component synthesized by the muscle cells. $B$, Densitometric scans of lanes $(i$, solid line) and (ii, dashed line) in A, quantitating the decrease in NCAMPSA (long arrow to asterisk), and the increase in NCAM-180 (short arrow). The arrowhead indicates material derived from the muscle cells. $C$, CG neurons cultured either alone $(N)$ or on a fibroblast monolayer $(N+F)$ culture. Note that the amount of endo N-sensitive NCAM is not affected by coculture with fibroblasts.

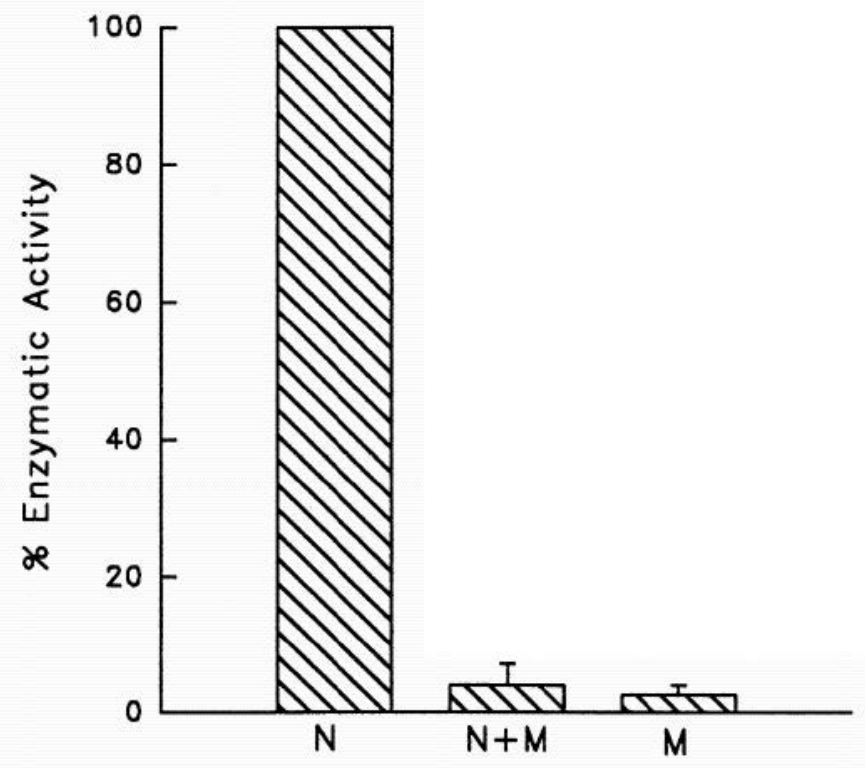

Figure 9. Effect of myotubes on neuronal polysialyltransferase activity in cultures; $6 \times 10^{5} \mathrm{CG}$ neurons were cocultured with myotubes for $3 \mathrm{~d}$ and then PST activity was measured by an specific polysialyltransferase activity assay. The results are expressed as the percentage of the enzymatic activity detected in neurons cultured alone. $N$, Neurons; $N+M$, neurons cocultured with myotubes; and $M$, myotube culture. Data are the mean value $\pm \mathrm{SE}$ from two independent experiments performed in duplicates.

romuscular junctions (Crean et al., 1982). The neurons were cultured for $3 \mathrm{~d}$, pulse-labeled with ${ }^{35} \mathrm{~S}$-methionine, and their NCAM immunoprecipitated and separated by SDS-PAGE. The autoradiogram of this material is shown in Figure $8 A(\mathrm{~N})$. If left in the embryo for this amount of time, these neurons would be at St 36-37 and thus would have downregulated their expression of PSA (Fig. 2B, lanes 5 and 6). In fact, when the neurons were cocultured for $3 \mathrm{~d}$ in the presence of the muscle cells, PSA addition to NCAM was sharply reduced (Fig. $8 A, \mathrm{~N}+\mathrm{M}$ ). There also appeared to have been a reduction in the overall levels of NCAM-180 being synthesized in the cultures with muscle. Such a decrease could correspond to the lower level of NCAM staining observed at St 37 in vivo (Fig. 1C). By contrast, in cultures without a target (Fig. 8A, N), the motorneurons produced NCAM with a high content of PSA. Densitometric scans of these results are shown in Figure $8 B$, with the solid line corresponding to neurons alone and the dashed line being neurons with muscle. To evaluate if this downregulation of PSA expression was specifically due to the muscle cells, CG neurons were also cocultured for $3 \mathrm{~d}$ with skin fibroblasts. As shown in Figure $8 C$, the expression of neuronal PSA was not affected by the presence of fibroblasts (compare $\mathrm{N}$ and $\mathrm{N}+\mathrm{F}$ ), suggesting that specific interaction between the neurons and muscle is required for downregulation of PSA.

To determine if the effect of the cultured muscle on PSA synthesis was also due to a decrease in polysialyltransferase activity, this activity was measured for St 33 CG neurons that had been cocultured with muscle (Fig. 9). Transferase activity could be detected easily in neurons that had been cultured alone $(\mathrm{N})$, whereas the coculturing of neurons with muscle for three days $(\mathrm{N}+\mathrm{M})$ reduced the polysialyltransferase activity to very low levels. To test if cultured muscle could produce an inhibitory factor that directly inhibited PST activity, cultured muscle was 
homogenized and added to the enzyme reaction; no inhibitory effect was detected, suggesting that the effect of the muscle on neuronal PST is caused by the interaction between neurons and muscle cells which then presumably activates an intracellular pathway that modulates the activity of the enzyme.

\section{Discussion}

The aim of the present study has been to reveal the mechanism(s) by which PSA levels are regulated during neural development. For these studies the chick ciliary ganglion system has been used, in that it is a well-characterized system with only two populations of motoneurons that are synchronized in the timing of axonal outgrowth and synaptogenesis (Landmesser and Pilar, 1974, 1978; Pilar et al., 1980).

PSA expression on developing CG motoneurons in vivo was found to change during the periods of neuronal outgrowth, target innervation and synaptogenesis. When assessed by immunostaining, PSA was increased on CG neurons at the time that the axons are growing toward and just reaching their target (St 26), with the highest level of PSA expression being at the time that the axons are growing and branching within the target tissue (St 33) (Landmesser and Pilar, 1978; Meriney and Pilar, 1987). When assessed biochemically, the greater intensity and lower mobility of the polydisperse material running above $200 \mathrm{kDa}$ during innervation indicates that each NCAM during this time has on average more and longer PSA chains. Then during the subsequent formation of synapses, levels of PSA expression gradually decreased (St 37-42). This pattern of PSA upregulation during innervation and downregulation with synaptogenesis was more accurately defined in the analysis of newly synthesized NCAM-PSA by pulse-label studies. That is, the NCAM being synthesized during innervation was found to be fully polysialylated (St 26-33), whereas during synaptogenesis the newly synthesized NCAM contained very little PSA (St 36-40).

The downregulation of PSA would appear to require synaptic activity, in that blockade of neuromuscular activity by in ovo treatment with $\alpha$-BTX prevented the developmental downregulation of PSA synthesis. This result is analogous to the ability of curare to increase PSA expression, axon sprouting and synaptogenesis by spinal cord motoneurons (Landmesser et al., 1990; Dahm and Landmesser, 1991). Although $\alpha$-BTX prevents naturally occurring cell death in both ciliary and choroid neurons, neuromuscular transmission of choroid neurons, being muscarinic, is not affected by $\alpha$-BTX, suggesting a direct effect of the drug on the neurons (Meriney and Pilar, 1987; Meriney et al., 1987). Thus, it is possible that the $\alpha$-BTX only affects PSA expression by ciliary neurons, which is the population that exhibits the most dramatic developmental downregulation of PSA. However, it remains that the effect of $\alpha$-BTX on PSA could also include mechanisms other than blockade of the neuromuscular activity, such as an increase in intracellular free $\mathrm{Ca}^{2+}$ in CG neurons via binding to a nicotinic receptor (Vijayaraghavan et al., 1992). A similar situation may also exsist for curare, in that this drug can directly alter the pattern of firing of chick spinal cord motoneurons (Landmesser and Szente, 1986).

The correlation of PSA upregulation with the innervation process may reflect the need for more plasticity in the bundling and branching of axons within the target. Conversely, the downregulation of PSA during synaptogenesis suggests that such plasticity is no longer desirable. The situation in the CG is therefore consistent with the previous studies of spinal cord motoneuron axons, where the highest level of PSA is detected at the time the axons are sorting in the plexus region and branching in the muscle (Landmesser et al., 1988, 1990; Tang et al., 1992, 1994).

Using this system, three potential mechanisms for control of PSA synthesis were evaluated: alteration of the NCAM substrate by addition of the VASE exon, altered pathways of receptor recycling, and changes in the level of polysialyltransferase. As neural tissues mature, the VASE exon is added between exons 7 and 8 in NCAM, thereby changing the fourth Ig domain from a C-type to a V-type (Small and Akeson, 1990). It has been noted that the insertion of VASE roughly correlates with the disappearance of PSA in neural tissues (Small and Akeson, 1990; Oka et al., 1995). In this study, we have examined whether VASE could be responsible for the developmental downregulation of PSA in CG motoneurons. However, no VASE exon was detected at any stage of embryonic development in the $C G$, suggesting that the presence of VASE is not a major factor in the developmental regulation of PS $\Lambda$ in this system.

Another possible avenue for alteration of NCAM-PSA would be recycling of NCAM from the membrane back through the Golgi for continued addition of sialic acid, as observed for the transferrin receptor and sialoglycoprotein-1 (Snider and Rogers, 1985; Hull et al., 1991). If full polysialylation of NCAM requires multiple passages through the Golgi, then regulation of the number of such recycling could contribute to changes in the amount of PSA on NCAM. However, each such recycling involves a half-time of 2-4 hr (Snider and Rogers, 1985; Hull et al., 1991), and our pulse-chase experiments with cultured CG neurons indicated that complete polysialylation of NCAM occurs within $90 \mathrm{~min}$ and does not change over the next $8 \mathrm{hr}$. Furthermore, the long half-life of NCAM at the cell surface (approximately $1 \mathrm{~d}$ ), suggests that recycling is an unlikely mechanism for regulation of PSA.

NCAM polysialylation may occur in one or several steps that could involve one or more enzymes (Kitazume et al., 1994; Eckhardt et al., 1995; Nakayama et al., 1995). To evaluate the role of polysialyltransferase(s) in the developmental regulation of NCAM polysialylation, an enzymatic assay was developed in which the incorporation of ${ }^{4} \mathrm{C}-\mathrm{N}$-acetylneuraminic acid into exogenous purified NCAM was used as an indicator of PST activity. Using this method, an increase in PST activity was detcetcd in $\mathrm{CG}$ tissue at the time that an increase in newly synthesized PSA on NCAM was observed (St 33), and the decrease in PST activity thereafter correlated well with the downregulation of PSA expression from St 36 to St 40 .

In order to determine if the downregulation of PSA is at least in part dependent on interaction with the peripheral target, cocultures of CG neurons with myotubes were used to demonstrate that neuronal NCAM-PSA synthesis is sharply decreased by the presence of muscle cells. This effect, which by SDS-PAGE analysis was very similar to the decrease in NCAM polysialylation in the embryo between stages 33 and 37, was cell-type specific in that neurons cocultured with a fibroblast monolayer did not change their level of PSA synthesis. The relationship between transferase activity and polysialylation of NCAM was also apparent in the downregulation of PSA in cocultures of CG neurons with myotubes. That is, specific PST activity was readily detected in cultures of neurons alone, but completely suppressed by the presence of myotubes.

Target-dependent regulation of neuronal enzymes has also been observed in other studies. For example, several target tissues have been found to produce cytokines that induce changes in the synthesis of neurotransmitters (see Patterson and Nawa, 
1993; Schotzinger et al., 1993), and in the CG, it has been observed that activin $\mathrm{A}$ in choroid-conditioned medium increases the expression of somatostatin (Coulombe et al., 1993). Therefore, it is possible that cytokines or related substances are involved in the target-dependent regulation of PSA expression by altering the expression of enzymes involved in PSA biosynthesis.

In conclusion, we have shown that the developmental expression of PSA is regulated by the interaction of neurons with the target tissue during synaptogenesis and that this regulation is produced through changes in the levels of PST activity. As yet it has not been determined whether the interaction between motoneurons and muscle involves a contact-dependent process and/ or a soluble factor. The intracellular pathways that lead to the control of PST enzyme levels also remains to be identified. However, the establishment of a reliable and quantitative in vitro assay for the regulation should now make such analyses possible.

\section{References}

Acheson A, Sunshine JL, Rutishauser U (1991) NCAM polysialic acid can regulate both cell-cell and cell--substrate interactions. J Cell Biol 114:143-153.

Alcaraz G, Goridis C (1991) Biosynthesis and processing of polysialylated NCAM by AtT-20 cells. Eur J Cell Biol 55:165-173.

Brusés JL, Pilar GR (1995) Effect of cycloheximide and mRNA synthesis inhibition on death of trophically deprived ciliary ganglion neurons in culture. $J$ Neurophysiol, in press.

Coulombe JN, Schwall R, Parent AS, Eckenstein FP, Nishi R (1993) Induction os somatostatin immunoreactivity in cultured ciliary ganglion neurons by activin in choroid cell-conditioned medium. Neuron 10:899-906

Crean G, Pilar G, Tuttle JB, Vaca K (1982) Enhanced chemosensitivity of chick parasympathetic ncurons in co-culture with myotubes. J Physiol (Lond) 331:87-104.

Crossin KL, Edelman GM, Cunningham BA (1984) Mapping of three carbohydrate attachment sites in embryonic and adult forms of the neural cell adhesion molecule. J Cell Biol 99:1849-1855.

Dahm LM, Lanmesser LT (1991) The regulation of synaptogenesis during normal development and following activity blockade. J Neurosci 11:238-255.

Eckhardt M, Muhlenhoff M, Bethe A, Koopman J, Frosch M, GerardySchahn R (1995) Molecular charaterization of eukaryotic polysialyltransferase-1. Nature 373:715-718.

Goodman CS, Shatz CJ (1993) Develomental mechanisms that generate precise patterns of neuronal connectivity. Cell $72 /$ Neuron 10(Suppl):77-98.

Hallenbeck PC, Vium ER, Yu F, Bassler B, Truy FA (1987) Purification and properties of a bacteriophage-induced endo- $\mathrm{N}$-acetylneuraminidase specific for poly- $\alpha-2,8$-sialosyl carbohydrate units. J Biol Chem 262:3553-3561.

Hamburger V, Hamilton HL (1951) A series of normal stages in the development of the chick embryo. J Morphol 88:49-93.

Hull SR, Sugatman ED, Spielman J, Carraway KL (1991) Biosynthetic maturation of an ascites tumor cell surface sialomucin. J Biol Chem 266:13580-13586.

Kitazume S, Kitajima K, Inoue S, Inoue Y, Troy FA (1994) Developmental expression of trout egg polysialoglycoproteins and the prerequisite $\alpha 2,6$, and $\alpha 2,8$-sialyl and $\alpha 2,8$-polysialyltransferase activities required for their synthesis during oogenesis. J Biol Chem 269: $10330-10340$.

Laemmli UK (1970) Cleavage of structural proteins during the assembly of the head of bacteriophage T4. Nature 227:680-685.

Landmesser L, Pilar G (1974) Synaptic transmission and cell death during normal ganglionic development. J Physiol (Lond) 241:737749.

Landmesser L, Pilar G (1978) Interactions between neurons and their targets during in vivo synaptogenesis. Fed Proc 37:2016-2022.

Landmesser L, Szente M (1986) Activation patterns of embryonic chick hind-limb muscles following blockade of activity and motoneurone cell death. J Physiol (Lond) 380:157-174.

Landmesser L, Dahm L, Schultz K, Rutishauser U (1988) Distinct roles for adhesion molecules during innervation of embryonic chick muscle. Dev Biol 103:645-670.

Landmesser L, Dahm L, Tang J, Rutishauser U (1990) Polysialic acid as a regulator of intramuscular nerve branching during embryonic development. Neuron 4:655-667

McCoy RD, Vimr ER, Troy FA (1985) CMP-NeuNAc:poly- $\alpha-2,8$-sialosyl sialyltransferase and the biosynthesis of polysialosyl units in neural cell adhesion molecules. J Biol Chem 260:12695-12699.

Meriney SD, Pilar G (1987) Cholinergic innervation of the smooth muscle cells in the choroid coat of the chick eye and its development. J Neurosci 7:3827-3839.

Meriney SD, Pilar G, Ogawa M, Nuñez R (1987) Differential neuronal survival in the avian ciliary ganglion after chronic acetylcholine receptor blockade. J Neurosci 7:3840-3849.

Nakayama J, Fukuda M, Fredette B, Ranscht B, Fukuda M (1995) Expression cloning of a human polysialyltransferase that forms the polysialylated N-CAM present in embryonic brain. Proc Natl Acad Sci USA 92: in press.

Nelson RD, Bates PA, Rutishauser U (1995) Protein determinants for specific polysialylation of the neural cell adhesion molecule. $J$ Biol Chem 270:17171-17179.

Oka S, Bruses JL, Nelson RW, Rutishauser U (1995) Properties and developmental regulation of polysialyltransferase activity in the chicken embryo brain. J Biol Chem 270:19357-19363.

Patterson PH, Nawa H (1993) Neuronal differentiation factors/cytokines and synaptic plasticity. Cell 72/Neuron 10(Suppl):123-137.

Pilar G, Landmesser L, Burstein L (1980) Competition for survival among developing ciliary ganglion cells. J Neurophysiol 43:233-254.

Rougon G (1993) Structure, metabolism and cell biology of polysialic acid. Eur J Cell Biol 61:197-207.

Rutishauser U (1995) The neural cell adhesion molecule and its unusual polysialic acid moiety. Sem Dev Biol 6:97-104.

Rutishauser U, Landmesser L (1991) Polysialic acid on the surface of axons regulates patterns of normal and activity-dependent innervation. Trends Neurosci 13:528-532.

Schneider C, Neuman RA, Sutherland DR, Asser U, Greaves MF (1982) A one-step purification of membrane proteins using a high efficiency immunomatrix. J Biol Chem 257:10766-10769.

Schotzimger R, Yin X, Landis S (1993) Target determination of neurotransmitter ohenotype in sympathetic neurons. J Neurobiol 25:620639.

Small SJ, Akeson R (1990) Expression of the unique NCAM VASE exon is independently regulated in distinct tissues during development. J Cell Biol 111:2089-2096.

Small SJ, Haines SL, Akeson RA (1988) Polypeptide variation in an NCAM extracellular immunoglobulin-like fold is developmentally regulated through alternative splicing. Neuron 1:1007-1017.

Snider MD, Rogers OC (1985) Intracellular movements of cell surface receptors after endocytosis: resialylation of asialo-transferrin receptor in human erythroleukemia cells. J Cell Biol 100:826-834.

Tang J, Landmesser L (1993) Reduction of intramuscular nerve branching and synaptogenesis is correlated with decreased motorneuronal survival. J Neurosci 13:3095-3103.

Tang J, Landmesser L, Rutishauser U (1992) Polysialic acid influences specific pathfinding by avian motorneurons. Neuron 8:1031-1044.

Tang J, Rutishauser U, Landmesser L (1994) Polysialic acid regulates growth cone behavior during sorting of motor axons in the plexus region. Neuron 13:405-414.

Troy FA (1992) Polysialylation: from bacteria to brains. Glycobiology 2:5-23.

Walsh FS, Dicksom G (1989) Generation of multiple NCAM polypeptides from a single gene. Bioessays 11:83-88

Vijayaraghavan S, Pugh PC, Zhang Z, Rathouz MM, Berg DK (1992) Nicotinic receptors that bind $\alpha$-bungarotoxin on neurons raise intracellular free $\mathrm{Ca}^{2+}$. Neuron 8:353-362.

Watanabe M, Frelinger AL, Rutishauser U (1986) Topology of NCAM structural and functional determinants. I. Classification of monoclonal antibody epitopes. J Cell Biol 103:1721-1727.

Yang P, Yin X, Rutishauser U (1992) Intercellular space is affected by the polysialic acid content of NCAM. J Cell Biol 116:1487-1496.

Yang P, Major D, Rutishauser U (1994) Role of charge and hydration in effects of polysialic acid on molecular interactions on and between cell membranes. J Biol Chem 269:23039-23044 